\title{
Technological knowledge in early childhood education: provision by staff of learning opportunities
}

\author{
Pernilla Sundqvist ${ }^{1}$ iD
}

Accepted: 31 January 2019 / Published online: 14 March 2019

(c) The Author(s) 2019

\begin{abstract}
Developments in early childhood education (ECE) over the last two decades have for many countries meant a change towards a more subject-oriented pedagogy in which preschool staff are commissioned to teach technology to young children. This has been proved to be a challenge to the staff. Through analysis of activities at two preschool units, this study shows how technology education can be provided in ECE, and what kind of knowledgelearning by children can be facilitated in different activities and depending on the actions of the staff. An ethnographically-inspired perspective was employed, using methods such as participant observation and formal and informal interviews, in order to investigate the technological knowledge encouraged by the staff at two preschool units in Sweden. The results show that staff promote children's learning of a variety of technological content, mainly relating to technological objects and creative processes. This range from simple knowledge of how to handle a knife or a pair of scissors to more complex knowledge of how to build something to be fit for purpose and how different tools or materials are more or less adequate for a specific activity or design. The result also show that the way in which the staff address these contents effect which abilities and skills children are promoted to develop.
\end{abstract}

Keywords Technology education - Technological knowledge · Early childhood education · Preschool $\cdot$ Preschool teacher $\cdot$ Preschool staff

\section{Introduction}

Developments in early childhood education (ECE) over the last two decades have for many countries meant a change towards a more subject-oriented pedagogy (Broström 2017; Van Laere et al. 2014). This change could be described as a slide from the social pedagogic tradition (Bennett 2005) with a holistic view on children's learning and development towards a greater focus on children's cognitive abilities and teaching children specific subjects. One of these subjects is technology, which is included in the Swedish curriculum with goals to

Pernilla Sundqvist

pernilla.sundqvist@mdh.se

1 School of Education, Culture, and Communication, Mälardalen University, Box 883, 72123 Västerås, Sweden 
strive for (Swedish National Agency for Education 2016). In Swedish preschool however, the term subject is exchanged for goal area or content area. Technology as content area has a practical nature and includes elements, such as building and making, which historically have always been included in preschool practice. This could therefore benefit adjustment towards the more subject-oriented pedagogy in which the curriculum articulates that children should be encouraged to explore and investigate technology in different ways. However, research points out a couple of challenges in this regard. Firstly, although some studies show teaching is happening in preschool but that preschool teachers do not call it teaching (see e.g. Sæbbe and Pramling Samuelsson 2017; Jansen 2008), other studies show that prioritising and teaching subject specific content seems to be difficult for preschool teachers (see e.g. Thulin 2011; Sundberg et al. 2016) and scrutinies have found teaching of technology is scarce (Swedish Schools Inspectorate 2012, 2017). Secondly, this particular subject is vaguely defined and lacks any long-standing teaching tradition or academic discipline from which to take guidance (Hagberg and Hultén 2005). These challenges would be present for any country where ECE is transitioning from the social pedagogic tradition to the inclusion of more subject learning. The question, in relation to the curriculum, is thus whether teachers in preschool have managed to broaden teaching to also include activities where children get to investigate, discuss and reflect on technology.

In view of this, it is interesting and important to investigate how preschool staff meet the task of teaching technology to children, focusing here on knowledge in technology (defined below). This is investigated by analysing data from two preschool units. The study aims to answer the following research question:

Which types of technological knowledge are promoted in staff's provision of learning opportunities for children, and how?

In order to investigate this research question, I will turn to the area of philosophy which includes components ideal for inspiring a theoretical framework for technology education (Norström 2014a; de Vries 2016). Norström (2014a) and Houkes (2009) have reviewed a number of systems for classifying the nature of technological knowledge. From their findings, it is decided here that the classification system provided by Hansson (2013) is the most relevant for the purpose of this study, and it will accordingly be applied in the analysis. However, this describes how something is known. Because technological knowledge consists of both how and what-aspects (de Vries 2016), for the technological content-the what-aspect-a framework describing technology education in preschool in terms of what children should learn (Sundqvist 2016) will be used. This framework was developed from empirical data. The two frameworks are presented in the literature background and will complement each other in analysis of the technological knowledge encouraged in the two preschool units.

\section{Knowledge in technology in ECE}

A great deal of preschool's technology content area includes knowledge in technology (Swedish National Agency for Education 2016) (as opposed to knowledge about technology, see Norström 2014b). Knowledge in technology relates to skills, knowhow and propositional knowledge, that is, knowledge required for performing technological actions (Norström 2014b). Technological actions are summarised by Turja et al. (2009, p. 358) as consisting of "producing-designing, inventing and constructing/ fabricating-, maintaining and troubleshooting, and using and selecting technology". 
This content is expressed in the preschool curriculum (Swedish National Agency for Education 2016, p. 10) as follows: "the preschool should strive to ensure that each child develops their ability to build, create and construct using different techniques, materials and tools", relating mainly to skills and know-how but also to propositional knowledge, and to "explore how simple technology works", relating to propositional knowledge. Furthermore, with regard to knowledge in technology, when advancing to compulsory school, children are expected to develop their ability to "analyse technological solutions based on their suitability and function, and identify problems and needs that can be solved by means of technology, and work out proposals for solutions" (Swedish National Agency for Education 2011, p. 254). Knowledge in technology is referred to by Norström (2014b) as technological knowledge. In this paper, the two are used interchangeably.

\section{Knowledge in technology according to Hansson's classification system}

Hansson (2013) has created a classification system for knowledge in technology expressed in terms of how one knows what one knows. He divides this technological knowledge into four categories: tacit knowledge, practical rule knowledge, technological science and applied science. Tacit knowledge is what we know intuitively and by practice, a skill that is difficult to explain in words, like riding a bike. It is learnt by imitating someone who possesses that skill. In some cases the skill has been articulated with the purpose of being more easily accessed, for instance by a textbook writer. The articulation of the skill then becomes practical rule knowledge. Practical rule knowledge is what we know from an instruction or from experience of what works in order to get a particular result, though without knowing why it works, such as using one spoon of ground coffee for each cup and then one extra when brewing coffee because that is the general "rule of thumb" for making good coffee. Practical rule knowledge and rule of thumb are used synonymously by Hansson. Technological science refers to knowledge obtained from the systematic study of technological solutions in order to identify their properties. This study employs scientific methods, often experiments, and concerns both the study of existing technology and the development of new technology through engineering design. In developing new technology, the engineer works with a list of criteria and goals for the solution and often has to make compromises between conflicting criteria. Applied science is when knowledge, primarily from natural scientific findings and mathematics, is used to explain, create or trouble-shoot a technological construction or solution (Hansson 2013).

Hansson also describes how easy or difficult each of these types of technological knowledge is to learn and points out practical rule knowledge as the easiest, followed by technological science and applied science. Tacit knowledge is the most difficult knowledge to learn because it cannot be directly applied from verbal instruction, but rather it requires extensive training.

Hansson (2013) believes that children in compulsory school should be given the opportunity to develop all of these types of knowledge. However, Norström (2014a) argues that applied science should be excluded from school technology (hence also from preschool) because it requires a knowledge of mathematics and science that the students do not yet possess. 


\section{Previous research in early childhood technology education}

Turja et al. (2009) show in their analysis of early childhood curricula in some European countries that knowledge in technology is included in early technology education in these countries-more specifically that they include the functions, properties and components of technological objects, materials, substances and physical phenomena, systems and processes for production and scientific and technological ways of working. The authors argue that several of these contents can be addressed through creative work in which the emphasis is on the creative process, rather than the product.

Several studies have found that children, in their play and in their investigations of artefacts, ask questions about artefacts, explain how artefacts work and act to make the artefact work the way they intend it to (Bairaktarova et al. 2011; Evangelou et al. 2010). Children also act in accordance with the different stages in the engineering design process when challenged with a problem by the teacher (van Meeteren and Zan 2010). Cunningham and Hester (2007, referenced in van Meeteren and Zan 2010) describe these steps with a set of questions in order to guide the work within each step as follows: "Ask: What is the problem? What have others done? What are the constraints? Imagine: What are some solutions? Brainstorm ideas. Choose the best one. Plan: Draw a diagram. Make lists of materials you will need. Create: Follow your plan and create it. Test it out! Improve: Talk about what works, what doesn't, and what could work better. Modify your design to make it better. Test it out!" When engaging in this design process to solve a problem (one problem stated by the teacher was "I wonder what you could figure out to get these objects to move" (ibid.), the children used, repeated and skipped steps depending on the problem or question under investigation. The authors therefore suggest that for children in ECE, the different stages could be considered components rather than steps.

In relation to this, Stables (2017) highlights the importance of the design process being iterative, rather than linear with a set of predefined steps, and encourage children to reflect upon and develop their design idea throughout the whole process. In line with Mawson (2013), she discusses the importance of having a balance between teacher and child direction and she argues for a holistic approach with children having ownership of the task that is to be set in an authentic and meaningful context. Also Bottrill (1995) acknowledges the importance of the child having ownership of the design task. In this, she points out the advantage of the early childhood education where teachers are not restrained by demand of being able to assess children's learning outcomes. However, Siegler and Alibali (2005) have found that children as young as five have difficulties considering several variables at the same time. Thus, design tasks that require the child to consider more than one or two variables for the product to be fit for purpose will be problematic for the child and, if to be successful, demand a high level of scaffolding. A possible alternative could be that the teacher provides an appropriate task that only includes one or two variables, but that means taking some of the ownership away from the child. Studies have also found the planning component to be a critical part where children are in need of support. van Meeteren and Zan (2010) found children seldom produced a proper plan for their construction. This finding is partly in line with Fleer (2000), who found that children as young as 3 years old are able to make design plans in the form of lists and sketches, but encountered difficulty when moving on to the construction phase because their plans were not sufficiently detailed. Mawson (2013) stresses that an important task for teachers is to support children in clarifying their idea and construction plan and to reflect on the creative process. The more common 
approach in the social pedagogic tradition has otherwise been to let children play and explore on their own, without much teacher interaction, in the belief that learning happens automatically in the course of play (Bennett 2005; Broström 2017).

Sundqvist (2016) conducted a questionnaire and interview study with the aim of finding out what technological content Swedish preschool staff consider appropriate for preschool technology education. The questionnaire used a stratified random sampling method and was followed with interviews in order to clarify and deepen some participants' responds. The results were presented in the form of categories and subcategories. In the following, these categories and subcategories are presented with a description/ example of what they include:

\section{Artefacts and systems in children's environments}

1.1 Learning to handle artefacts: Using common objects such as scissors, cutlery and computer tablets.

1.2 Learning the application areas and adequacy of artefacts: Discussing which tool is best for taking the soup or the spaghetti and why; testing and talking about different ways of using an object; finding new ways to use an object.

1.3 Learning the purpose of artefacts: Not putting out cutlery for lunch in order to start a discussion about how humans invented cutlery in order to meet their desire not to eat with their hands.

1.4 Learning how artefacts and systems work: Taking apart objects; experimenting with solar cell-driven toys; following water and how it is purified, from the lake to the tap.

\section{The creative process}

2.1 Building and creating: Building cars; building with Lego. Here, no learning objective or purpose for the building activity was given.

2.2 Learning about materials: Learning how materials can be used in different creations; how they can be attached; training the ability to handle different materials.

2.3 Learning to build and create by practicing: Building techniques e.g. how to build stable constructions; painting techniques with different painting tools.

2.4 Learning a specific content by building and creating: Building and creating is one of many methods to learn about a content, any content, perhaps within a project.

2.5 Solving a problem by building/creating a solution: Children create a solution to a problem. The problem can originate from their own play or from a challenge provided by a teacher. This may promote children's confidence and awareness that a problem can have more than one solution.

2.6 Learning how something is produced: Talking about how materials from the garbage that we sort are recycled and used for making new things; how an artefact or material is made, such as toilet paper.

3. Learning what technology is: A meta level. What do you mean when you say technology? Teachers talk about technology as technology in order to support children's developing understanding of the concept.

4. Learning techniques: In Swedish, the word for technology is a homonym that refers to both technology and technique. In this category the second meaning is intended: how people use their bodies to achieve a desired result, e.g. children run, climb and jump. 
5. Learning natural science and other content areas: Two perspectives. First: technology is not distinct from other areas, meaning that activities provided and described as technology may teach something else, such as natural science. Second: activities viewed as technological activities (e.g. experiments, construction play) are used as means for learning other content, despite being described as technology.

Sundqvist's (2016) study shows a broad range of technological content described by preschool staff, with a focus on artefacts and building activities. The categories include simple everyday activities, such as using cutlery when eating lunch, and building activities that seem to have no purpose from the staff's point of view. They also include more complex content, such as exploring the adequacy of artefacts and materials, how artefacts and systems work, and what makes a stable construction. The study also shows that content addressing areas other than technology is described as technology education by preschool staff.

\section{Methodology}

The design of the study was inspired by an ethnographic perspective. Copland and Creese (2014) talk about an ethnographic perspective rather than ethnography when the researcher studies a (for him/her) familiar context and thereby spends a shorter amount of time in the field than what is usual in ethnographic research, as was the case here. In accordance with the ethnographic perspective, a variety of methods were used with the aim of understanding the setting and the people within it in relation to their actions (Hammersley and Atkinson 2007). Spending time in the studied practices and being close to the participants allowed for the development of this understanding.

\section{Participants}

The aim of the study was to see how staff in preschool work to provide opportunities for children to develop their technological knowledge. This aim requires the studied preschools to actually have some kind of technology education. Since scrutinies (Swedish Schools Inspectorate 2012, 2017) has found this not always to be the case, I turned to the network for mathematics and technology pilots in the investigated municipality and enquired about interest in participation in the study. This is a network that works to inspire the development of preschools' mathematics and technology education and includes preschool staff with specific responsibility for the subject areas of mathematics and technology. These preschool staff are called mathematics and technology pilots. Two preschool units responded and were included in the study. Preschool unit 1 employed two preschool teachers and one childcare attendant, and the 16 children were 3-5 years old. Preschool unit 2 employed one preschool teacher and two childcare attendants, and the 19 children were all 5 years old. Preschool teachers and childcare attendants are two different professional groups in Sweden, with only preschool teachers having a university degree. When referred to collectively, I will refer to them as preschool staff. 


\section{Data generation}

Methods used were participant observation (the type described as "observer as participant" by Bryman 2008) and interviews, both formal and informal. Conversations initiated by the participants were also used as data. Where both child and legal guardians gave informed consent, video recordings were used for documenting observations in order to capture both auditory and visual details (Heath et al. 2010). Elsewhere field notes were used, though there was no documentation of the children whose legal guardians had not given their consent. Where field notes were used, brief notes were taken during the observation and expanded on later the same day or the next day while the observation was still fresh in the memory. One formal one-on-one interview was conducted with each preschool teacher. We watched a video, which we selected together, in which the preschool teacher had performed some kind of technology activity with the children. The intention was to let each of them explain the aim of the activity and their thoughts about how they performed that activity (Meade and McMeniman 1992). All formal interviews were recorded. Informal interviews and conversations initiated by the participants occurred spontaneously when it was felt, by myself or a participant, that there was a need for something to be explained about the participants' actions or about the practice or their teaching methods more generally.

I spent 10 days at preschool 1 and 9 days at preschool 2, 3-6 h each day, over a period of 6 weeks.

\section{Data analysis}

As previously mentioned, in order to identify the types of technological knowledge where preschool staff promoted children's learning, Hansson's (2013) classification for technological knowledge, together with Sundqvist's (2016) framework, was used in the analysis. Sundqvist's (2016) framework was based on a questionnaire and interview study in which preschool staff answered questions about what they considered appropriate content for technology education in preschool. The framework includes anything that these preschool staff described as technology education and thus contains some aspects not applicable for the purpose of this study since they do not describe a technological goal or content. These are categories 4 and 5 and subcategories 2.1 and 2.4, and they where not used for analysis here.

All data, from the two preschool units, were treated as one unit. Observations were the main source of data. The data included a total of $6 \mathrm{~h}$ of video recorded observations, 22 pages of field notes (including observations and informal interviews) and $1.5 \mathrm{~h}$ of formal interviews were analysed. As a first step of the analysis, videos and interviews were transcribed. These data contained 53 observed activities. Due to the focus on the staffs' actions aimed at providing learning opportunities for the children, only observations of activities in which at least one staff member was included in some way were analysed. When the data had been sorted in relation to this criterion, 45 activities remained. The 45 activities were analysed using Hansson's technological knowledge and 32 of these were found to promote at least one of Hansson's four types of technological knowledge. Each activity showing staff acting to promote any one of Hansson's categories was extracted and then further analysed for technological content using Sundqvist's (2016) framework. Performing the analysis in this order entailed a primary focus on technological knowledge from a philosophical perspective. 
As shown in Table 1 below, activities where staff promoted tacit knowledge and practical rule knowledge were observed. For transparency reasons, I will now provide examples of how the analysis was performed with regard to Hansson's four types of technological knowledge. For an activity to be interpreted as promoting tacit knowledge it should involve children being given an opportunity to practice a skill, a skill which they had not yet conquered. This is because the aim was to study how the staff supported the children in developing tacit knowledge. As described in the literature background, practical rule knowledge and rule of thumb are used synonymously by Hansson. Rule of thumb has been given a clear definition by Norström $(2011$, p. 97) as "an ordered set of statements describing actions that will lead to a certain result in the right context. They should be interpreted as: these actions, performed in this order, will bring this result about". This type of knowledge can be gained through instruction or experience. When the staffs' actions were interpreted as promoting practical rule knowledge, they either provided instructions in the way described by Norström (2011, p. 97) as a rule of thumb or encouraged the child to investigate in a manner that resulted in an experience based practical rule knowledge. So, with the category of learning to build and create as an example, if a child wanted to paint something pink and there was only red, yellow, blue and white paint, the teacher used practical rule knowledge in the first sense if she said: "Mix red and white and you will get pink". However, if the teacher said something like: "It is possible to get a new colour by mixing colours together. See if you can make pink by mixing some of the colours you have" and thereby encouraged the child to investigate and test how pink can be made, then she promoted practical rule knowledge in the second sense. For an activity to be interpreted as promoting technological science, a more systematic experimental method including components such as repeated trials and control groups to test a construction or investigate some specific issue or hypothesis would have been observed. Lastly, for an activity to be interpreted as applied science it should include the same as for technological science and also rely on verified scientific theories and models.

In the following, Sundqvist's (2016) categories defined as "Learning to..." are changed to "Knowledge to..." in order to harmonise with Hansson's terminology. Also the term "artefacts" used in Sundqvist's framework is changed to "technological objects", which is considered more appropriate. Technological objects are defined as human made objects and systems (Mitcham 1994).

\section{Trustworthiness of the study}

Qualitative studies are primarily based on the researcher's interpretation of data (Bryman 2008). This entails a risk that the researcher's prior knowledge and experiences are allowed to bias the analysis. The choice to use not only field notes but also video recordings reduced this risk in the data generation process. In analysing the data, the use of theoretical frameworks to guide the analysis was a way to reduce this risk. Also other steps were taken in order to ensure the quality of the study by following recommendations from Bryman (2008). In the analysis with Hansson, some parts of the data were difficult to categorise. These parts were sent to a colleague who is familiar with the two frameworks used in the analysis. He read it and we discussed how to categorise the material until consensus was obtained. This categorisation identified activities promoting practical rule knowledge in the second sense described above as technological science. This initial understanding was due to Hansson's argument that children in compulsory school should get to develop all of the four types of technological knowledge that he describes, thus the assumption was 
made that technological science is not as advanced as it turned out to be. Later, the categorisation was also discussed with another colleague who is more of an expert on Hansson's classification of technological knowledge. This resulted in a revision of the categorisation which ultimately was performed in line with the above description.

The analysis was written down as preliminary results and sent to the participants who were also asked to read it. A meeting was then set up with the participants at which the preliminary results were discussed and the participants were invited to comment on them. The purpose of this meeting was to ensure that I had understood the participants' intentions and actions correctly. Following this meeting, adjustments were made to the analysis in respect of the participants' intentions in relation to two activities.

Ultimately, the method has been described as clearly as possible in order to achieve transparency and thus facilitating the assessment of its dependability.

\section{Compliance with ethical standards}

The study was conducted in accordance with current ethical standards (Swedish Research Council 2017). Initial information about the study was sent out to all the mathematics and technology pilots in the municipality. This included a short description of the aim and methods of the study. Prior to the start of the study, I visited the two preschool units that had expressed an interest, and they were given a more complete description of the study, as well as information about voluntary participation, and were told that the material and personal data would be treated confidentially. All preschool staff $(n=6)$ at these two units gave informed consent. However, at the start of the study, one participant, the child care attendant at preschool unit 1 , withdrew her consent and was excluded from the study. Information was also sent to the legal guardians of all the children at each unit. They were asked to consent to their children's participation. Consent was obtained for 29/34 children. No documentation was produced for the children whose legal guardians did not give consent. The children at the two preschool units were informed of the purpose of my presence on the first day of the fieldwork. The staff gathered all the children and I told them who I was and why I was there. I showed them my camera and asked if it was okay for me to film them. They all said yes. During the fieldwork I was observant of the children's reactions to my presence and to the camera. Only at one time did a child ask me to leave, which I did. Otherwise, the children never displayed any discomfort at my presence, but only curiosity about the camera.

\section{Results}

Firstly, in order to provide an overview, the technological knowledge addressed in the two preschool units is shown in Table 1. Examples from the data are then presented in order to show how different types of technological knowledge were promoted. 


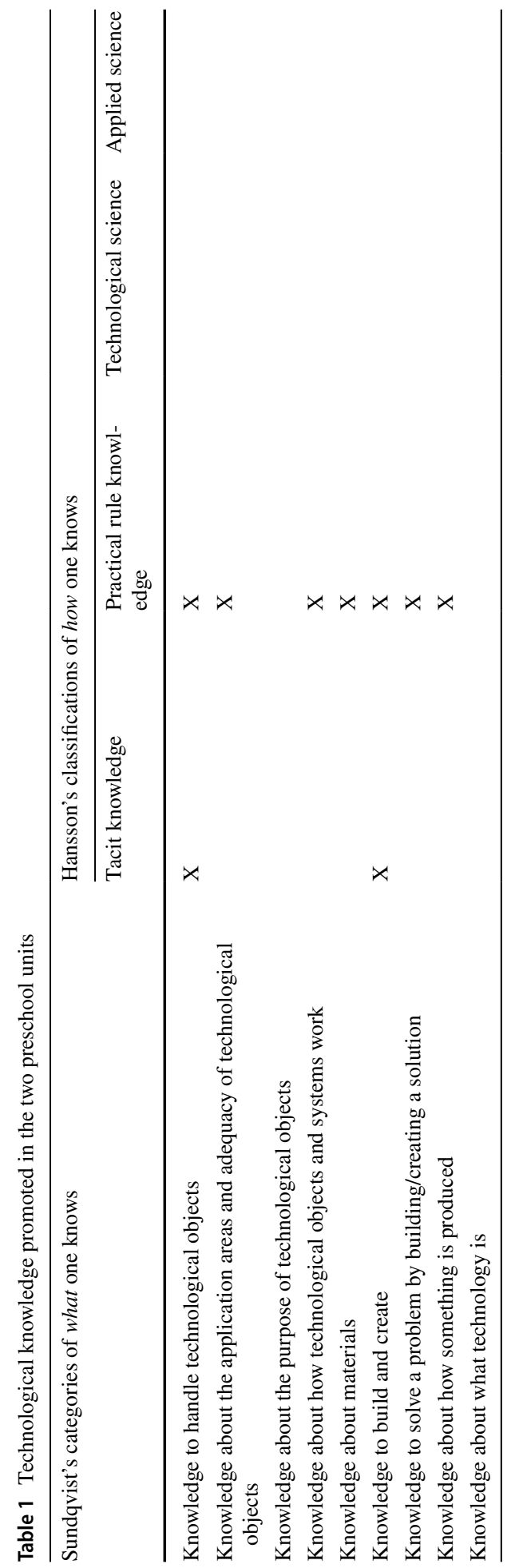




\section{Tacit knowledge}

Tacit knowledge was encouraged in relation to learning to handle technological objects such as the scissors, knives and pens. Cutting with scissors is a familiar activity to most children, but cutting along a line, such as when cutting out characters in order to create play materials, demands specific sensitivity and fine motor skills. This is a skill that staff encouraged by giving children lots of opportunities, and time to practice. Cutting with a knife can be done in different ways depending on what is to be cut. In a gingerbread-baking activity, the children used a knife to cut out the dough around the template. It could be imagined that children are used to cutting their food with a knife, however this kind of cutting seemed to be new to them. The preschool teacher helped the children by showing how it is done, making it possible for them to imitate her, and by trying to articulate how to do it, thereby transforming the tacit knowledge into practical rule knowledge in order to make it easier to teach:

P: "Now we take the knife [she takes it out] and we cut around [she shows]".

The child takes the knife and starts to cut.

P: "You need to cut just on the edge here".

The child holds the knife a bit clumsily with both hands. The teacher takes the knife and shows how she should hold it.

P: "Like this with the tip down, just like you do when you draw" (Video transcript, 171,206, preschool 1).

Another way in which staff supported children's development of tacit knowledge was observed when a child was asked to write his name on the baking paper in order to know which gingerbread is his. The preschool teacher wrote the child's name on a piece of paper so he could imitate it, but he had difficulty forming the letters. The preschool teacher then took his hand, with the pen still in the child's hand, and helped him to form the letters.

Tacit knowledge was also observed in relation to knowledge of how to build and create. In the gingerbread-baking activity, children were asked to knead and roll their dough, which they found challenging. One preschool teacher assisted the children in her group by using her own dough to show how it is done. Another preschool teacher helped her group of children first by warming the dough in the microwave, making it softer and easier to handle, and then using her own dough to demonstrate. She also gave suggestions on how to get more force when rolling out the dough, such as kneeling on the chair and putting their hands on top of the middle of the roller instead of holding the handles. Nevertheless, some children ultimately needed help from the teacher in order to finish rolling out the dough.

Another occasion when the above-mentioned content was observed was during an activity in which the children made Christmas decorations. Inspired by the childcare attendant, one child wanted to make a Christmas card with a pop-up action. Cutting and folding the card correctly demanded a tacit knowledge and the childcare attendant supported the child by demonstrating and trying to verbalise the required knowledge. She therefore used both a show-imitate method and practical rule knowledge in order to enable the child to complete the task. The child tried several times before she got it right. 


\section{Practical rule knowledge}

Practical rule knowledge was observed to be promoted in three ways: by staff providing practical rule knowledge by giving instructions, by staff encouraging children to articulate practical rule knowledge by giving each other instructions and by children to create their own practical rule knowledge by investigating and testing.

Preschool staff providing children with practical rule knowledge by giving instructions was observed on several occasions. They used practical rule knowledge to teach children about how to handle technological objects, about the application areas and adequacy of technological objects, about materials, about how to build and create, about how to solve a problem by building/creating a solution, and about how something is produced.

Knowledge about how to handle the computer tablet was often taught with practical rule knowledge. On one occasion four children were gathered around a tablet using a drawing application. When the first child had finished his drawing, he wanted to save it. The preschool teacher who was sitting nearby instructed him in how to save his drawing, a sequence of actions in three steps, by saying: "Save yes, can you push save, the save button. And then at the top there, at the very top, and then you press OK. Now you can close it". The child did another drawing and when he was finished, the preschool teacher asked if he wanted to save it, which he did. She said: "You know how to do it now" and he performed the three steps on his own.

Staff were also observed to encourage children to articulate practical rule knowledge. An example of this that relates to the content area of knowledge to build and create, was when a child, during a movie project, was about to make a paper pocket to store her movie characters in. She asked the preschool teacher to explain how to make it. The preschool teacher told her to ask a friend who had made a paper pocket the day before. The friend, who was told and shown by the preschool teacher with practical rule knowledge the previous day, was now able to pass on the instructions to the first child, who was then able to make the paper pocket.

It was also observed how practical rule knowledge was developed by children through their own investigations and creative activities. This was either done on the children's own initiative, or by staff encouraging children to investigate or test something in order to find a solution to some technological problem.

One example is when the first snow had come and the children wanted to go on the bum sliders. The preschool teacher identified a need for a snow slope and proposed that they build a slope together. During the building, she made the children aware of how the slope needed to be designed in order to be fit for purpose. When the children thought the slope was ready, the preschool teacher said they now had to test it to see if it worked properly. The children tested the slope and noticed that they got stuck in the middle of the slope. The preschool teacher pointed out two possible reasons: the design of the slope or the children's technique when going on the bum sliders. They tested, evaluated and modified the slope. During the building of the slope, one child recognised another problem: How are they going to get up to the top of the slope? He had identified a sub-function that he addressed. $\mathrm{He}$ and a friend started to build stairs at one end of the snow slope. He then asked another friend to test it and when the friend went up the stairs one step broke. The child noticed this and told the preschool teacher about it. The two children then continued to work on the stairs to improve them. In this activity, we thus see how the preschool teacher engaged the children in the engineering design process in building the slope and how children did the same on their own in building the stairs. The activity provides many possibilities for 
including technological content. The ones observed here were handling technological objects, with children using different tools to carry snow, the application area and adequacy of technological objects being implicitly addressed by the teacher talking about the snow sleighs as more appropriate for shovelling snow than the spades the children initially used, and the children themselves finding alternative tools for moving snow, e.g. one child carried snow in a bum slider. The knowledge required to build and create was addressed as children were given the opportunity to learn how to build a snow slope fit for going down with bum sliders and, because the whole activity stems from a need/desire that is to be met, knowledge to solve a problem by building/creating a solution is also included.

In another situation, a preschool teacher initiated an activity in which she intended the children to build something that could roll. The children wanted to build busses. They used milk cartons as a frame structure and the lids from the milk cartons for wheels. In order to get the wheels to roll easily they attached straws to the frame structure and then put plant sticks in the straws and glued the wheels to the plant sticks. The teacher demonstrated using a model that she had already started working on and tried to explain to the children why they did it this way.

P: "I started here to see how it would work, look I'm going to show you." She takes out a milk carton to which she had attached axles in plain bearings (plant sticks in straws). She removes the straw and the plant stick from the milk carton and shows the children.

P: "To make the wheels spin, if you do it like this, I use these for wheels (she holds up a lid and places it against the end of the straw), then maybe it won't spin so I think it is better to have a stick". She puts the stick inside the straw.

P: "Look, you put this in here and the stick spins in here". She spins the stick and puts a lid against the stick to show where it will go (Video transcript, 171,116, preschool 1).

The final example in which staff encouraged a child to develop her own practical rule knowledge was described to me by a preschool teacher after I had seen and asked about a new playhouse in the preschool unit that looked like it had been made by a child. She told me a child came to her the day before with a binder which they keep with the creative materials. The binder contains lots of pictures of things to make from the creative materials available in the creative area. She explained that it works as a source of inspiration for the children. This child had found a house in the binder that she wanted to build. The preschool teacher told her to draw a picture of what she wanted her house to look like, which she did. They then talked about what she needed in terms of materials to build the house and fetched the materials. Finally the child built the house. So, instead of just telling the child to build the house as it is in the picture, the teacher encouraged the child make her own plan, to think about what she wanted her house to be like and to make a sketch. The initial picture was used as inspiration. 


\section{Discussion}

The study investigated the types of knowledge in technology that the staff in two preschool units gave children opportunities to learn. As this is a small-scale study, recruiting its participants from a network of mathematics and technology pilots who can be expected to have more knowledge about how to teach technology to young children than other preschool teachers in general, the results of the study cannot be expected to be representative for ECE in general. Instead, the results should be viewed as examples of how technology education can be performed in ECE and what kind of knowledge-learning for children can be facilitated in different activities depending on the actions of the preschool staff. The introduction showed technology education in preschool is a challenge to many preschool staff, the results can therefore be used by preschool staff for reflecting on their own practice and teaching, as well as by researchers to inform new studies in this, yet, under-researched area.

In the discussion that follows, I will briefly address what was not observed in the study, and then move on to discuss what was observed.

As can be seen from Table 1, the content of Sundqvist's (2016) subcategory 1.3, Knowledge about the purpose of technological objects, and category 3, Knowledge about what technology is, was not observed. Nor was Hansson's (2013) technological science and applied science. The absence of Sundqvist's categories 1.3 and 3 is explained by the fact that this content cannot be addressed by any of Hansson's four types of technological knowledge. The categories relate to knowledge about technology, rather than knowledge in technology (as defined by Norström 2014b). The absence of applied science is in accordance with what Norström (2014a) suggests and can probably be explained with his argument that this knowledge type is too complex for children of this age group. Probably, the lack of technological science can be explained with the same argument. This would mean that Hansson's classification system for technological knowledge is not appropriate for analysing teaching on ECE level because all teaching addresses two out of four types of knowledge. Thus, if the results would be presented only concerning which types of technological knowledge preschool staff promotes, without further description of how this promotion is performed, it would not say much. However, as the results show there is a diversity in how technological knowledge is promoted that has consequences for what abilities and skills children are encouraged to develop which is not shown with Hansson's categories.

With tacit knowledge, it is (motor) skills that are developed. Having the necessary (motor) skills is a precondition for children's ability to perform technological actions such as using and producing technology (Norström 2014b). Providing practical rule knowledge through instruction not only promotes the ability to understand an instruction, but it also enables children to easily help each other. ECE, specifically in the Nordic and Central European countries who follow the tradition of the social pedagogic approach (Bennett 2005), values children's opportunities to learn from each other. The participants in this study also expressed this ambition. Providing practical rule knowledge through instruction thus promotes children's abilities to help and teach each other because it is easy for them to understand, use and pass on. This is shown here in the example with the making of the paper pocket. Encouraging children to develop their own practical rule knowledge in the way the study has shown promotes abilities to identify problems, make proposals for ideas and plan designs, investigate, reflect and draw conclusions. This accords with the preschool curriculum stating that children should be provided opportunities to explore and investigate technology (Swedish National Agency for Education 2016). Furthermore, these abilities 
accord with the objectives of compulsory school technology education, meaning working with these give children a head start for primary technology education (Swedish National Agency for Education 2011). The results also show that when children are encouraged to develop their own practical rule knowledge through investigation and building activities many of Sundqvist's (2016) technological contents are included in the same activity. Hence, these activities seem to be full of potential for rich learning and teaching possibilities, in line with what Turja et al. (2009) suggested.

This promotion for children to develop their own practical rule knowledge could be described as staff encouraging children to perform investigations inspired by a technological science method or experiment, using Hansson's (2013) meaning of technological science. They test to see whether a certain process or design will provide the intended function, but they do not repeat their tests, use control groups or any other of the required components for a "real" experiment. In this perspective, these activities could be described as emergent technological science methods on an ECE level. In other areas, such as literacy (Whitehurst and Lonigan 2002) and science (Siraj-Blatchford 2001), the term emergent have been applied to describe the learning process that occurs before the formal learning. For example, emergent literacy regard the processes that occur from the time when the child is very young, through many different reading and play activities that relate to texts in different ways, to the time of formal schooling when the child becomes literate (Whitehurst and Lonigan 2002). In emergent literacy, the preschool teacher for instance sits down with children and reads to them, and rhymes with the children in order to develop their phonological awareness, which is a precursor to literacy. In this study, the preschool staff sat down with children and built things with them and encouraged children to make plans and test their ideas in line with the simplified engineering design process described by Cunningham and Hester (2007, referenced in van Meeteren and Zan 2010), which they consider a precursor to engineering. Siraj-Blatchford (2001) also puts forward the specific characteristics for teaching at ECE level, including elements like children's perspectives and play. In emergent science and technology, he suggests children should be provided opportunities to play scientists and technologists. In this study we see children doing this as they include the engineering design process in their play. Siraj-Blatchford also describes a consensus in the UK concerning the idea that children should be taught the nature of science and the processes of scientific knowledge construction, which he relates to emergent science, rather than being taught scientific facts. Translating these ideas to technology, the activities observed in this study can be described as encouraging and engaging children in emergent technological science activities.

\section{Conclusion}

The study has shown the staff promote children's learning of a variety of technological content, mainly relating to technological objects and creative processes. These activities range from simple knowledge of how to handle a knife or a pair of scissors to more complex knowledge of how to build something to be fit for purpose and how different tools or materials are more or less adequate for a specific activity or design. The way in which the staff address these contents effect which abilities that are promoted. It has been observed here that technological activities promote children's motor skills, ability to follow and to give instructions, ability to identify a problem and to plan and perform actions to solve the problem, investigate, draw conclusions and reflect on technological objects and processes. 
In all of these cases there is an active preschool staff involved who supports children's learning in different ways. Thus, the staff in this study were seen on several occasions to provide children with the support suggested by van Meeteren and Zan (2010), Fleer (2000) and Mawson (2013).

The study suggests that one type of activity provide especially rich learning possibilities, i.e. activities that include the design process. It was observed how activities of this type promoted investigation and learning of many technological contents. We also know that activities of this type hold the potential to promote a holistic and integrated learning in many areas such as science, mathematics, language, arts and from different perspectives like societal and environmental ones (Bottrill 1995; Stables 2017; Thorshag and Holmqvist 2018). While preschool in some countries are somewhat sliding away from the social pedagogic approach, the ambition to sustain a holistic and integrated approach to learning remains. It thus seems important to, both in research and practice, explore the full potential of different activities in preschool, such as design and making activities, taking a broader point of departure in the curriculum to include a variety of content areas and abilities. A collaboration between practice and research, perhaps through action research, would be a possible way.

\section{Compliance with ethical standards}

Conflict of interest The author declares that he/she have no conflict of interest.

Open Access This article is distributed under the terms of the Creative Commons Attribution 4.0 International License (http://creativecommons.org/licenses/by/4.0/), which permits unrestricted use, distribution, and reproduction in any medium, provided you give appropriate credit to the original author(s) and the source, provide a link to the Creative Commons license, and indicate if changes were made.

\section{References}

Bairaktarova, D., Evangelou, D., Bagiati, A., \& Brophy, S. (2011). Early engineering in young children's exploratory play with tangible materials. Children, Youth and Environments, 21(2), 212-235.

Bennett, J. (2005). Curriculum issues in national policy-making. European Early Childhood Education Research Journal, 13(2), 5-23.

Bottrill, P. (1995). Designing and learning in the elementary school. International Technology Education Association.

Broström, S. (2017). A dynamic learning concept in early years' education: a possible way to prevent schoolification. International Journal of Early Years Education, 25(1), 3-15.

Bryman, A. (2008). Social research methods (3rd ed.). Oxford: Oxford University Press.

Copland, F., \& Creese, A. (2014). Linguistic ethnography: Collecting, analysing and presenting data. Los Angeles: Sage.

de Vries, M. J. (2016). Teaching about technology. An introduction to the philosophy of technology for nonphilosophers (2nd ed.). Cham: Springer.

Evangelou, D., Dobbs-Oates, J., Bagiati, A., Liang, S., \& Choi, J. Y. (2010). Talking about artifacts: Preschool children's explorations with sketches, stories, and tangible objects. Early Childhood Research and Practice, 12(2), 1-16.

Fleer, M. (2000). Working technologically: Investigations into how young children design and make during technology education. International Journal of Technology and Design Education, 10(1), 43-59.

Hagberg, J.-E., \& Hultén, M. (2005). Skolans undervisning och elevers lärande i teknik—svensk forskning $i$ internationell kontext. [School's teaching and pupils' learning in technology-Swedish research in an international context]. Stockholm: Vetenskapsrådet.

Hammersley, M., \& Atkinson, P. (2007). Ethnography: Principles in practice (3rd ed.). London: Routledge. 
Hansson, S.-O. (2013). What is technological knowledge? In I.-B. Skogh \& M. J. de Vries (Eds.), Technology teachers as researchers (pp. 17-31). Rotterdam: Sense publishers.

Heath, C., Hindmarsh, J., \& Luff, P. (2010). Video in qualitative research: Analysing social interaction in everyday life. Los Angeles: Sage.

Houkes, W. (2009). The nature of technological knowledge. In A. Meijers (Ed.), Philosophy of technology and engineering sciences (pp. 309-350). Amsterdam: Elsevier.

Jansen, T. T. (2008). En lærer underviser, men hva gjør en førskolelærer? [A teacher teaches, but what does a preschool teacher do?]. In R. J. Pettersen (Ed.), Barnehagen som laringsarena (pp. 27-44). Oslo: Pedagogisk forum.

Mawson, B. (2013). Emergent technological literacy: What do children bring to school? International Journal of Technology and Design Education, 23(2), 443-453. https://doi.org/10.1007/s10798-011-9188-y.

Meade, P., \& McMeniman, M. (1992). Stimulated recall-An effective methodology for examining successful teaching in science. Australian Educational Researcher, 19(3), 1-18.

Mitcham, C. (1994). Thinking through technology: The path between engineering and philosophy. Chicago: University of Chicago.

Norström, P. (2011). Technological know-how from rules of thumb. Techné, 15(2), 96-109.

Norström, P. (2014a). Technological knowledge and technology education. [Doctoral thesis], KTH Royal Institute of Technology, Stockholm.

Norström, P. (2014b). How technology teachers understand technological knowledge. International Journal of Technology and Design Education, 24(1), 19-38.

Sæbbe, P.-E., \& Pramling Samuelsson, I. (2017). Hvordan underviser barnehagelærere? Eller gjør man ikke det i barnehagen? [How do preschool teachers teach? Or do they not teach in the preschool?]. Tidskrift för Nordisk barnehagsforskning, 35(14), 1-15.

Siegler, R. S., \& Alibali, M. W. (2005). Children's thinking (4th ed.). New Jersey: Prentice-Hall Inc.

Siraj-Blatchford, J. (2001). Emergent science and technology in the early years. Paper presented at the XXIII world congress of OMEP. Santiago Chile.

Stables, K. (2017). Holistic approaches to learning, teaching and assessment in technology education: Authenticity, challenges, supportive approaches and tools. Paper presented at the TENZ-ICT, Chirstchurch, New Zealand.

Sundberg, B., Areljung, S., Due, K., Ekström, K., Ottander, C., \& Tellgren, B. (2016). Understanding preschool emergent science in a cultural historical context through activity theory. European Early Childhood Education Research Journal, 24(4), 567-580.

Sundqvist, P. (2016). Teknik i förskolan är inget nytt, men idag är vi mera medvetna om vad vi kallar teknik. Personalens beskrivningar av teknik som innehållsområde $i$ förskolan. [Technology in preschool is nothing new, but today we are more aware of what we call technology. The staff's descriptions of thechnology as content area in preschool]. [Licentiate Thesis]. Mälardalen University, Västerås.

Swedish National Agency for Education. (2011). CurrIculum for the compulsory school, preschool class and the recreation centre 2011. Stockholm: Swedish National Agency for Education.

Swedish National Agency for Education. (2016). Curriculum for the preschool, LPFÖ 98, revised 2016. Stockholm: Swedish National Agency for Education.

Swedish Research Council. (2017). God forskningssed. [Good Research Practice]. Vetenskapsrådets rapportserie 1:2011. Stockholm.

Swedish Schools Inspectorate. (2012). Förskola, före skola-lärande och bärande. Kvalitetsgranskningsrapport om förskolans arbete med det förstärkta pedagogiska uppdraget. [Preschool, pre schoollearning and baring. Quality review on the preschool's work with the enhanced pedagogical assignment]. https://www.skolinspektionen.se/globalassets/0-si/01-inspektion/kvalitetsgranskning/forsk ola-2011/kvalgr-forskolan2-samf.pdf. Accessed 201803.

Swedish Schools Inspectorate. (2017). Förskolans arbete med matematik, naturvetenskap och teknik. [The preschool's work with mathematics, science and technology]. https:/www.skolinspektionen.se/sv/ Beslut-och-rapporter/Publikationer/Granskningsrapport/Kvalitetsgranskning/forskolans-arbete-medmatematik-teknik-och-naturvetenskap/. Accessed 032018.

Thorshag, K., \& Holmqvist, M. (2018). Preschool children's expressed technological volition during contruction play. International Journal of Technology and Design Education. https://doi.org/10.1007/ s10798-018-9481-0.

Thulin, S. (2011). Lärares tal och barns nyfikenhet: Kommunikation om naturvetenskapliga innehåll i förskolan. [Teachers' talk and children's curiosity: communication about natural scientific content in the preschool]. [Doctoral Thesis]. Gothenburg University, Gothenburg.

Turja, L., Endepohls-Ulpe, M., \& Chatoney, M. (2009). A conceptual framework for developing the curriculum and delivery of technology education in early childhood. International Journal of Technology and Design Education, 19(4), 353-365. 
Van Laere, K., Vandenbroeck, M., Roets, G., \& Peeters, J. (2014). Challenging the feminisation of the workforce: Rethinking the mind-body dualism in Early childhood education and care. Gender and Education, 26(3), 232-245.

van Meeteren, B., \& Zan, B. (2010). Revealing the work of young engineers in early childhood education. Presented at SEED (STEM in Early Education and Development), Iowa, USA.

Whitehurst, G. J., \& Lonigan, C. J. (2002). Emergent literacy: Development from prereaders to readers. In S. B. Nueman \& D. K. Dickinson (Eds.), Handbook of early literacy research. New York: The Guilford Press.

Publisher's Note Springer Nature remains neutral with regard to jurisdictional claims in published maps and institutional affiliations. 